\title{
A POLIFONIA PROCESSUAL: UMA APROXIMAÇÃO DO PROCESSO PENAL E DO INTERROGATÓRIO DO ACUSADO COM A METODOLOGIA EMPREENDIDA PELA ESCOLA DOS ANNALES
}

\author{
Luiz Gustavo Gonçalves Ribeiro ${ }^{1}$
}

Resumo: O propósito do texto é aproximar, para fins de assunção de um processo penal democrático, a revolução empreendida pela Escola dos Annales nas Ciências Sociais à construção, em contraditório, do provimento jurisdicional. Assim, todos os envolvidos, e também o acusado, seriam, juntamente com o juiz, formadores da decisão jurisdicional, havendo, portanto, uma verdadeira polifonia. À pergunta se o pensamento dos Annales representa referência para a construção da sentença à luz da Constituição, tem-se a hipótese de que quanto mais polifonia e participação houver no processo, mais democrática será a decisão. A pesquisa é teórica, jurídico-dogmática, e o raciocínio é lógico-dedutivo.

Palavras-chave: Processo penal; Escola; Annales; contraditório; provimento.

\section{THE PROCESSUAL POLYPHONY: AN APPROACH TO THE CRIMINAL PROCESS AND THE INTERROGATORY OF THE ACCUSED WITH METHODOLOGY EMPLOYED BY THE SCHOOL OF ANNALS}

\begin{abstract}
The purpose of text is to approximate, for purposes of assumption of a democratic criminal procedure, the revolution provide by School of Annales in Social Sciences to the construction, in contradiction, of the jurisdictional provision. Thus, all those involved, and so also the accused, would be, along with the judge, formators of judicial decision, and therefore, a true polyphony. To the question of whether the Annales' thinking is a reference for construction of sentence in Constitucional reason, one has the hypothesis that more polyphony and participation there is in the process, more democratic the decision will be. The research is theoretical, legal-dogmatic, and reasoning is logical-deductive.
\end{abstract}

Keywords: Criminal proceedings; School; Annales; contradictory; provision.

\section{INTRODUÇÃO}

\footnotetext{
${ }^{1}$ Doutor e Mestre em Ciências Penais pela UFMG. Pós-Doutor em Direito Constitucional pela Università Degli Studi di Messina-IT. Professor do Programa de Mestrado em Direito Ambiental e Desenvolvimento Sustentável da Escola Superior Dom Helder Câmara. Promotor de Justiça em Belo Horizonte-MG. Endereço postal: Rua General Dionísio Cerqueira, 147/302, Gutierrez, Belo Horizonte-MG. Endereço eletrônico: lgribeirobh@gmail.com
} 
Muito impressiona o artigo de Peter Burke sobre a história polifônica (BURKE, 2000). O texto, de linguagem simples e objetiva, demonstra a perspectiva atual dos historiadores e cientistas sociais modernos, mormente a partir da revolução operada por Lucien Febvre, Marc Bloch, Fernand Braudel e outros com a Escola dos Annales ${ }^{2}$, de interessar-se por narrativas polifônicas que enfatizam os diversos pontos de vista dos múltiplos participantes de eventos em prejuízo de um discurso singular, isolado, de determinado partícipe ou interlocutor.

O interesse pelo texto surgiu de sua relação, pensada no momento da leitura do artigo, com o contraditório existente no processo - e a ênfase será dada ao processo penal - onde a pesquisa do fato-crime, importante para que o julgador possa aquilatar a culpa do acusado no momento de proferir a sentença, deve aproximar-se, tanto quanto possível, da realidade de como foram produzidos, isso desde o ponto de vista do acusado, da vítima e das testemunhas presenciais; daí o discurso polifônico que deve nortear o processo.

Como a busca por uma história total, global, ou seja, aquela relacionada à compreensão pela polifonia, pela necessidade de ultrapassar sistematicamente os limites de um problema desde o ponto de vista interdisciplinar, é marca típica da revolução operada pelos Annales, o trabalho intentará abordar a importância do contraditório no processo e no interrogatório do acusado, associando essa importância à teoria fazzalariana de processo como espécie de procedimento realizado em contraditório e com a inovação ocorrida no discurso histórico a partir dos Annales. O tema é atual e instigante e justifica-se pela necessidade de consolidar o paradigma constitucional do processo, mormente em face da quantidade de expedientes que pululam no Supremo Tribunal Federal em razão da conhecida operação Lava-Jato.

Sob a ótica de uma pesquisa teórica e interdisciplinar em que cotejados aspectos jurídicos com vertentes da evolução da História como ciência social, apresenta-se o texto, que principiará pela abordagem revolucionária proporcionada pela Escola dos Annales e sequenciará com o estudo do processo penal sob a ótica constitucional e a exposição da teoria Fazzalariana, marco teórico do trabalho, de processo como procedimento realizado em contraditório. Em seguida, focar-se-á na participação do acusado na formação do provimento jurisdicional com o escopo de, ao final, ser feita a associação entre a polifonia apregoada pelos Annales com a concepção fazzalariana de processo.

\footnotetext{
${ }^{2}$ Movimento intelectual de repúdio ao positivismo histórico e ao caráter narrativo da história tradicional inspirado por Lucien Febvre e Marc Bloch que fundaram, em 1929, uma revista, Annales d'histoire économique et sociale, com o propósito de divulgar uma nova maneira de fazer história.
} 


\section{A POLIFONIA PROCESSUAL: UMA APROXIMAÇÃO DO PROCESSO PENAL E DO INTERROGATÓRIO DO ACUSADO COM A METODOLOGIA EMPREENDIDA PELA \\ ESCOLA DOS ANNALES}

À pergunta se o pensamento dos Annales poderia representar uma referência para a construção do provimento jurisdicional no processo penal à luz da Constituição, tem-se a hipótese de que quanto mais polifonia e participação houver no curso do processo, mais democrática será a decisão proferida.

Alinha-se, assim, por meio do raciocínio lógico-dedutivo, a Escola dos Annales à Escola fazzalariana de processo.

\section{A REVOLUÇÃO PROPORCIONADA PELA ESCOLA DOS ANNALES}

Imperante no final do século XIX e no início do século XX, o positivismo histórico, que apregoa que o conhecimento histórico é proporcionado pelo retrato fiel, livre de qualquer fator subjetivo, de fatos passados (SCHAFF, 1978), foi o principal alvo de ataque de uma nova concepção intelectual originada na França, produto de um pequeno grupo associado à revista Annales, criada em 1929 com o título Annales d’histoire économique e sociale, e que foi fundada por dois jovens historiadores então lotados na Universidade de Estrasburgo, Lucien Febvre e Marc Bloch.

A revista, que ganhou a cara do espírito empreendedor de seus fundadores, visava promover uma nova forma de se fazer história e continua a encorajar inovações e trazer à baila a importância de despojar-se daquilo que é arcaico, não mais condizente com a realidade.

Brevemente sumariadas, as ideias diretrizes da revista foram elencadas por Peter Burke, em rica obra sobre o tema:

\footnotetext{
em primeiro lugar, a substituição da tradicional narrativa de acontecimentos por uma história-problema. Em segundo lugar, a história de todas as atividades humanas e não apenas história política. Em terceiro lugar, visando completar os dois primeiros objetivos, a colaboração com outras disciplinas, tais como a geografia, a sociologia, a psicologia, a economia, a linguística, a antropologia social, e tantas outras (BURKE, 1997, p. 11-12).
}

Visavam, pois, os Annales o combate à história tradicional marcada pela narrativa monofônica que enfatizava, a partir do mito da neutralidade e da separação sujeito-objeto estimulada pelo positivismo, a história política centrada na vida dos grandes homens, líderes políticos e militares em prejuízo de cidadãos comuns. Visavam, outrossim, o estímulo à crítica 
e, de forma a superar os limites dos problemas postos, criar a chamada história total em contraposição à abordagem factual realizada pelo tradicionalismo vigente até então.

Especificamente sobre a polifonia, tema sedutor por sua correlação com a ideia de contraditório que será estudada adiante, a Escola dos Annales representou a revolução pela recusa a uma história simplista que se limita ao estudo da superfície dos acontecimentos e a eles atribui um contorno factual ${ }^{3}$. Abandonaram-se as barreiras então existentes com as demais ciências sociais e o discurso passou a ser o de todas as camadas sociais numa perfeita ideia de que o homem é um ser social.

Daí porque, de volta ao artigo de Peter Burke referido alhures, não mais seria possível descrever, a partir da revolução operada pela Escola dos Annales, a história das mudanças sociais e culturais ocorridas de algum tempo para cá sem o apelo às narrativas “'multivocais’ ou 'polifônicas' em que diversas pessoas envolvidas nos [...] eventos ou [...] processos contam a história desses eventos ou processos de diversos pontos de vista” (BURKE, 2000, p. 18).

Apresentada a nova abordagem da história sob a perspectiva da história total, sua correlação com a tese de que a decisão jurisdicional proferida no processo penal deve ser fruto da comparticipação de todos os envolvidos na demanda e não apenas das concepções solipsistas do julgador, passa-se, no tópico seguinte, ao estudo do processo constitucional e à abordagem do contraditório no âmbito processual penal.

\section{PROCESSO E CONSTITUIÇÃO}

Sob uma perspectiva histórica, o processo surge da evolução dos primitivos meios de imposição da força pela autotutela. A lei do mais forte imperava sobre a do mais fraco que, assim, acabava sujeitando aos caprichos daquele, que fazia prevalecer o seu interesse pessoal em prejuízo alheio.

Nas eras primitivas, não havia um estado suficientemente forte, dotado de aparato capaz de suportar os anseios individualistas dos homens e impor o direito acima da vontade dos particulares (CINTRA; GRINOVER; DINAMARCO, 2003).

\footnotetext{
${ }^{3}$ Le Goff, referindo-se à posição e à ação dos Annales, entoa que houve grande mérito no combate ao marasmo da história que deveria, pelo apelo a uma história profunda e total, quebrar a história pobre, “[...] de aparência enganadora de pseudo-história”. (LE GOFF, 2005, p. 41).
} 


\section{A POLIFONIA PROCESSUAL: UMA APROXIMAÇÃO DO PROCESSO PENAL E DO INTERROGATÓRIO DO ACUSADO COM A METODOLOGIA EMPREENDIDA PELA ESCOLA DOS ANNALES}

Com o constitucionalismo, os estados passaram a reger-se por constituições soberanas, cuja superioridade não deriva de normas prévias, mas, ao contrário, condicionam a validade das leis. $^{4}$

Por constituir-se norma normarum, ${ }^{5}$ a Constituição vincula o próprio Estado, que deve respeitar, assim como os cidadãos, os preceitos nela estabelecidos. Como o reconhecimento e a proteção dos direitos do homem estão na base das constituições, nasce, então, uma obrigação estatal de criar mecanismos de proteção ao cidadão.

Norberto Bobbio, ao descrever a evolução histórica dos direitos do homem, revela que a característica marcante da formação do Estado moderno foi a inversão na relação entre este e os cidadãos: não se fala mais em interesse dos súditos, mas dos titulares de cidadania. Emerge daí uma maneira diversa de analisar a relação política, “não mais predominantemente do ângulo do soberano, e sim daquele do cidadão, em correspondência com a afirmação da teoria individualista da sociedade em contraposição à concepção organicista tradicional” (BOBBIO, 1992, p. 3).

O processo surge, nesse contexto, como a forma constitucional de racionalização e regulamentação do exercício das atividades estatais. ${ }^{6}$ Se cabe à Constituição assegurar e declarar direitos fundamentais dos cidadãos oponíveis ao Estado, compete-lhe, também, organizar a atividade estatal de modo a impedir agravos ao pleno exercício desses direitos. Sob a égide do processo, o cidadão encontra-se protegido das ingerências estatais que se submetem a regras prévias no Estado de Direito.

Essas ingerências ganham contornos especiais no processo penal. Estabelece-se nele um conflito de grandes dimensões não apenas porque o delito revela, de maneiras e intensidades diferentes, o drama da discórdia promovida entre o jus libertatis do cidadão e o poder-dever de punir estatal, "mas porque ele representa a relação que se desenvolve entre quem o comete, ou se supõe que o comete, e aqueles que assistem à sua perpetração.” (CARNELUTTI, 2002, p. 4).

\footnotetext{
${ }^{4}$ José Cirilo de Vargas chama a atenção para essa hegemonia constitucional: "A Constituição é que forma o arcabouço jurídico-político de toda Nação, contendo, ou não, regras democráticas. E para ninguém é novidade que a Constituição é que traça os pressupostos de todos os setores da ordem jurídica: com o Processo não poderia ser diferente. Os institutos fundamentais do Direito Processual refletem, evidentemente, o 'clima político' do País, expresso na Constituição". (VARGAS, 1992, p. 57).

${ }^{5}$ Referência de Canotilho em razão da superioridade hierárquica da Constituição sobre as leis. (CANOTILHO, 1993)

${ }^{6}$ Mais uma vez vale frisar a lucidez de José Cirilo de Vargas: “O fenômeno político antecede ao jurídico. Por isso, o instrumento de que vale o poder político para assegurar a efetividade do modelo adotado tem sido o direito. E o meio de que lança mão o poder para realizar o direito é o Processo [...]” (VARGAS, 1992, p. 58).
} 
Instituído por princípios e regras constitucionais, o processo penal apresenta-se como um "microcosmos democrático do Estado-de-direito, com as conotações da liberdade, igualdade e participação (contraditório), em clima de legalidade e responsabilidade.” (DINAMARCO, 2003, p. 27).

É por tal razão que Eugênio Pacelli, na introdução de sua obra, ressalta:

A ciência do processo penal brasileiro inicia o século XXI com pelo menos uma grande pretensão de certeza: a de que não é mais possível empreender qualquer pesquisa dogmática apartada do referencial constitucional. Aliás, mesmo no plano exclusivamente teórico, afastado de um específico sistema normativo, toda investigação que se queira fazer ao nível de uma teoria processual estará fadada, não ao insucesso de seus resultados possíveis, mas ao inevitável questionamento acerca da pertinência de seus propósitos, quando não inserida em determinado ordenamento constitucional. E isso se dá menos pela eventual incapacidade de rendimento da proposição que pela possibilidade de afastamento $a$ priori - na Constituição - de suas consequências. (OLIVEIRA, 2004, p. 1).

Também Andolina, sobre a raiz constitucional do processo, esclarece:

Na nova perspectiva pós-constitucional, portanto, o problema do processo não diz respeito somente ao ser (isto é, a sua concreta organização, segundo a lei ordinária vigente), mas também ao seu dever-ser (isto é, a conformidade de seu ordenamento positivo com a normatividade constitucional sobre o exercício da atividade jurisdicional). (ANDOLINA; VIGNERA, 1992, p. 5) ${ }^{7}$

E, em obra diversa, continua o autor italiano a dizer que "o processo é incessantemente chamado a questionar-se acerca do seu próprio grau de jurisdicionalidade e a adequar-se ao ‘modelo’ previsto pela Constituição.” (ANDOLINA, 1997, p. 65).

A leitura do texto constitucional revela que sua inspiração democrática resultou numa intenção nítida de proteger o indivíduo contra o arbítrio estatal. O sistema curador do cidadão é uma imposição do Estado democrático que, desde suas origens, representa superação daquele opressor, policiante, que ignora o jus libertatis do indivíduo.

\footnotetext{
${ }^{7}$ Tradução livre de: Nella nuova prospettiva post-costituzionale, quindi, il problema del processo non riguarda soltanto il suo essere (id est, la sua concreta orgazzazione secondo le leggi ordinarie vigenti), ma anche il suo dovere essere (id est, la conformità del sua asseto positivo alla normativa costituzionale sull'essercizio dell'attività giurisdicionale).
} 


\section{A POLIFONIA PROCESSUAL: UMA APROXIMAÇÃO DO PROCESSO PENAL E DO INTERROGATÓRIO DO ACUSADO COM A METODOLOGIA EMPREENDIDA PELA ESCOLA DOS ANNALES}

O dever do Estado de punir o infrator da norma penal deve corresponder ao direito do acusado de defender-se de forma ampla, por meio de um processo justo. Se não deve haver impunidade ou o arrefecimento dos órgãos estatais incumbidos da segurança pública, os direitos da pessoa investigada e processada devem ser respeitados segundo os ditames constitucionais.

Frederico Marques, sobre essa referência constitucional, revela:

Assentando-se na Constituição o conjunto de princípios básicos do processo penal, claro está que a Justiça Criminal na organização de seus quadros e no funcionamento de seus órgãos, tem de receber direto influxo dos valores éticos e políticos que informa a ordem jurídico-constitucional. Donde ser imprescindível, para a construção científica dos fundamentos normativos do Direito Processual Penal, a fixação dos princípios constitucionais e que defluem os seus diversos preceitos e que estruturam as suas categorias jurídicas. Para isto, não basta o exame isolado de textos em que se definem as garantias individuais. Necessário se torna que a Constituição seja examinada como um todo, a fim de que a dedução dos princípios e regras fundamentais traga em si uma perfeita harmonia com os valores supremos da Lei Maior. (MARQUES, 1998, p. 81).

O processo, diante desse paradigma constitucional determinante, não se apresenta apenas como garantia técnica e tampouco como meio para assegurar direitos, mas também como garantia ética, já que na raiz de seus princípios fundamentais encontra-se sempre um preceito constitucional (GRINOVER, 1985).

\subsection{Sobre o contraditório no processo penal}

Citando Rudolf Von Jhering para explanar que a ideia de contraditório não é recente, Aroldo Plínio Gonçalves (2001) sustenta ser o conceito de contraditório bem atual e não foi ainda totalmente assimilado, embora o seu princípio fundamental de "audita altera pars”, “audita altera parte”, “audi alteram partem” já esteja bastante presente na teoria geral do direito. Nas palavras do autor mineiro,

na segunda parte de sua 'Introduction à la Science du Droit (dividida em Encyclopédie Du Droit, em Théorie Générale Du Droit e em Introduction à la Philosophie du Droit)', PIERRE PESCATORE fala sobre le caractère contradictoire de la procédure, explicitando o adágio audiatur (...) et altera pars, que significa, 
conforme diz, que uma decisão não pode adquirir a autoridade da coisa julgada para quem não participou do debate judiciário, que o contraditório possibilita o melhor esclarecimento do juiz, e que, entretanto, significa, sobretudo, a possibilidade eu a parte deve ter de se fazer ouvir : 'Ce pricipe doit être entendu toutefois en ce sens que toute partie interessée doit avoir la possibilité de se faire entendre'. (GONÇALVES, 2001, p. 119-120). (destaques no original).

Com tal concepção, o contraditório aproxima-se de seu atual conceito, no sentido de não se limitar apenas à participação dos sujeitos no curso do processo, por ser ele

\begin{abstract}
a garantia de participação, em simétrica paridade, das partes, daqueles a quem se destinam os efeitos da sentença, daqueles que são os 'interessados', ou seja, aqueles sujeitos do processo que suportarão os efeitos do provimento e da medida jurisdicional que ele vier a impor. (GONÇALVES, 2001, p. 120).
\end{abstract}

E, tamanha é a importância do contraditório, que ele é a essência da distinção entre processo e procedimento, o que será abordado doravante.

\title{
3.2 A concepção de processo como procedimento realizado em contraditório
}

Elio Fazzalari, em Peruggia, no ano de 1958, realizou célebre prolusão, seguindo a linha de raciocínio de Benvenuti, ocasião em que afirmou ser o processo um esquema de procedimento mais complexo (NUNES, 2004).

Tencionou o ilustrado jurista italiano resgatar o processo de teorias que o consideravam um mero veículo ou método da atividade jurisdicional para produção de sentenças. Para tanto, contrapondo-se à noção de processo como relação jurídica e consoante o paradigma do vigente Estado Democrático de Direito, concebeu o processo como procedimento realizado em contraditório entre os interessados no provimento final do Estado.

É que, para o festejado autor, não se poderia aceitar que numa democracia as pessoas vivessem como mero espectadores, inertes aos assuntos que lhes dissessem respeito, sem que participassem ativamente do ato final do Estado, seja ele de natureza jurisdicional, legislativa ou administrativa ${ }^{8}$.

\footnotetext{
${ }^{8} \mathrm{O}$ raciocínio se justifica ainda mais em tempos de e-democracia, como ficou conhecida a democracia digital, por meio da qual a participação do cidadão é ainda mais facilitada (COSTA; SAMPAIO, 2017).
} 


\section{A POLIFONIA PROCESSUAL: UMA APROXIMAÇÃO DO PROCESSO PENAL E DO INTERROGATÓRIO DO ACUSADO COM A METODOLOGIA EMPREENDIDA PELA \\ ESCOLA DOS ANNALES}

Nesse sentido é a lição Habermas de que o Estado Constitucional constitui-se a partir

de “[...] uma ordem política livremente estabelecida pela vontade do povo de modo que os destinatários das normas legais podem, ao mesmo tempo, se reconhecerem como os autores da lei” (Habermas, 1995, p. 92) e de qualquer outro provimento, seja ele de natureza jurisdicional ou administrativa.

O processo deve ser, pois, analisado sob o paradigma do Estado de Direito, já que da mesma forma em que a legitimidade deste ocorre mediante a participação do povo na determinação de suas finalidades, diretrizes e decisões, também é a participação das partes interessadas que legitimará o provimento final a ser proferido, o que se dá mediante o contraditório.

Contudo, como dito alhures, não basta que seja assegurada às partes a garantia de participação na construção do provimento; é preciso que se garanta a elas também a participação em simétrica paridade, com igualdade de forças e de armas.

Já advertia Fazzalari, ao tratar o processo como procedimento em contraditório:

tale struttura consiste: nella partecipazione dei destinatari degli effetti dell'atto finale alla fase preparatória del medesimo, nella simmetrica parità delle loro posizioni, nella mutua implicazione delle loro attività (volte, rispettivamente, a promuovere ed a impedire l'emanazione dell'atto), nella rilevanza delle medesine per l'autore dell'atto: in modo che ciascun contradittore possa esercitare um insieme - cospicuo o modesto non importa - di scelte, di reazioni, di controlli, e debba subire i controlli e le reazioni degli altri, e che l'autore dell'atto debba tener conto dei risultati. Si pensi, per esempio, alla fase che precede una sentenza civile di condanna e nella quale si raccolgono gli elementi in base ai quali il giudice dovrà emanare tale sentenza o rifiutarla: ad essa partecipano colui che è destinato a subire la condanna e colui che è destinato ad esserne il beneficiário, in contradittorio fra loro, cioè svolgendo attività, fra loro simmetriche, volte a fornire al giudice - che non potrà non tenerne conto - elementi a favore e contro quella emanazione.

C’`e, insomma, 'processo' quando in una o più fasi dell'iter di formazione di un atto è contemplata la partecipazione non solo - ed ovviamente - del suo autore, ma anche dei destinatari dei suoi effetti, in contradittorio, in modo che costoro possano svolgere attività di cui l'autore dell'atto deve tener conto, i cui risultati, cioè, egli può disattendere, ma non ignorare (FAZZALARI, 1975, p. 29-30).

Observa-se, pois, que o processo se renova na ideia mesma de procedimento que traz consigo o contraditório, de suma importância para que a decisão final seja uma construção das 
partes em litígio. Assenta-se, pois, a teoria fazzalariana nos conceitos de provimento - ato imperativo do Estado emanado de órgãos que exercem o poder em suas diversas funções -, procedimento e processo, reconhecendo entre eles uma interligação necessária e de cunho lógico.

\subsection{A participação do acusado no processo: o ato do interrogatório}

Basta uma simples análise dos ritos processuais penais estabelecidos no ordenamento para que se possa perceber que o legislador não se descuidou de estabelecer, em qualquer deles, um momento próprio, peculiar, onde o acusado pudesse, de viva-voz, manifestar sua versão sobre os fatos a ele imputados.

Sobre a importância desse ato, que poderá ser decisivo para a formação do convencimento do julgador, Haddad, em precioso estudo sobre o tema, assevera que

\footnotetext{
o interrogatório é um tema que oferece um sem número de aspectos, muito mais extensos do que à primeira vista se apresentam. Vicente de Paulo Vicente de Azevedo diz ser o interrogatório o ato capital do processo. Altavilla declara, positivamente, que o interrogatório é o ato processual mais importante, visto que, tendo o processo como finalidade elementar a averiguação da culpa ou da inocência do acusado, é claro que toda a atividade desenvolvida por este deve ser o centro de polarização de qualquer investigação. No mesmo diapasão, Carnellutti afirma que não há prova, em processo penal, mais preciosa que o testemunho do acusado [...] (HADDAD, 2000, p. 73).
}

E dando ênfase a essa importância, destaca Altavilla, sobre o interrogatório: "quantas vezes o exame atento e sereno de um interrogatório pode fazer descobrir um indício importante, mesmo quando, para o observador superficial, parecia somente um seguro e desdenhoso protesto de inocência”. (ALTAVILLA, 1981, p. 12).

Em nenhum outro momento do processo ter-se-á um manancial de informações tão grande, pois não apenas acerca dos fatos será ouvido um seu participante, mas também colhidas impressões acerca do comportamento do acusado, seu semblante, seu tom de voz, o que revela ser de grande valor, inclusive para a própria defesa, mesmo porque, segundo a conveniência ou estratégia defensiva, poderá o acusado manter-se em silêncio.

Sensível à importância do interrogatório no processo penal, o legislador pátrio, embora já tardiamente, editou a Lei 10792/03 tornando necessária a presença do defensor do acusado 


\section{A POLIFONIA PROCESSUAL: UMA APROXIMAÇÃO DO PROCESSO PENAL E DO INTERROGATÓRIO DO ACUSADO COM A METODOLOGIA EMPREENDIDA PELA \\ ESCOLA DOS ANNALES}

no interrogatório, a prévia entrevista deste com aquele e, ainda, a possibilidade de que a defesa, assim como a acusação, na esteira do artigo 188, do Código de Processo Penal, participe ativamente do ato. Assim, o interrogatório, um dos atos mais importantes do processo, propicia a integração direta do acusado no constante diálogo que deve permear a formação do ato cogente do Estado, o que é imperativo para a correlação, a seguir apresentada, entre a polifonia da Escola dos Annales e o dever ser do provimento a ser proferido no âmbito do processo criminal.

\section{A POLIFONIA E A CONCEPÇÃO DE PROCESSO COMO PROCEDIMENTO REALIZADO EM CONTRADITÓRIO}

A concepção democrática de processo, adotada pelo ordenamento pátrio na esteira do sistema acusatório vigente, faz com que ele, processo, não deva ser um monólogo, mas um diálogo, um intercâmbio de ações e reações entre seus sujeitos, rico em estímulos e impulsos contrários, cuidando-se, pois, de um celeiro de argumentações (OLIVEIRA, 1993). Como já frisado, a tese fazzalariana de que processo é procedimento realizado em contraditório entre as partes escudou-se na ideia de que num Estado que se proclama democrático a tomada das decisões pelos governantes deve ser compartilhada com o povo. Assim, os destinatários das diretrizes desse Estado devem ser, bem como os litigantes num processo judicial, de uma forma ou de outra, consultados acerca do provimento final, do ato que produzirá efeitos na esfera própria de direitos.

Consoante tal premissa, Oliveira (1993), nos moldes da argumentação até então desenvolvida e falando sobre a postura do juiz diante do princípio do contraditório, fornece argumentos para que se defenda a necessidade do amplo debate, ainda e principalmente no interrogatório do acusado, dada a sua importância para justificar a decisão final:

\footnotetext{
Não se esqueça, contudo, que mesmo o Juiz mais competente não está inteiramente habilitado, sem a ajuda do advogado, a conduzir um processo complicado do ponto de vista prático. Ele não terá tempo e, ainda com a melhor boa vontade, o mesmo interesse dos representantes das partes, para classificar o material por elas trazido, processá-lo e formá-lo com independência (OLIVEIRA, 1993, p. 32).
} 
E mais adiante, continua, enfatizando a inexistência de uma nítida e rígida repartição de funções entre o juiz e as partes:

[...] da análise do que realmente se passa transparece claramente o entrelaçamento de ambas as atividades, com mútua colaboração tanto na pesquisa dos fatos quanto na valoração jurídica da causa. Colaboração essa, acentue-se, possibilitada apenas pelo permanente diálogo entre os sujeitos processuais, com a comunicação das idéias subministradas por cada um deles; juízos históricos e valorizações jurídicas que possam ser empregados convenientemente na decisão (OLIVEIRA, 1993, p. 33).

Não se pode falar, pois, em processo sem diálogo, ou melhor, sem que haja a participação equânime e garantida das partes, inclusive no interrogatório do acusado que hoje, nos moldes em que se encontra estruturado, é capaz de trazer aos autos a versão do processado sobre os fatos que lhe são imputados.

Ora, colocadas tais premissas, evidente é a aproximação existente entre a polifonia histórica, apregoada pela Escola dos Annales e sustentada por Burke, e a ideia do contraditório no processo tal como desenvolvida acima. Se a polifonia representa um discurso multivocal e se o processo deve desenvolver-se com a voz de todos os seus partícipes, não seria loucura nenhuma sustentar que a Escola dos Annales - ao revolucionar a maneira de fazer e pensar história de uma forma global, envolvendo o discurso de todas as classes sociais e rompendo as barreiras com as demais ciências sociais fomentando a interdisciplinaridade - introduziu o contraditório na história.

Nesse sentido, vale frisar o depoimento do festejado historiador José Carlos Reis (2000) sobre a revolução operada pela Escola dos Annales e sobre a constante intersubjetividade que deve permear o discurso histórico:

a história deixou de ser uma empresa intuitiva, fundamentada em a prioris indemonstráveis e passou a ser 'comunicável', criando as condições de uma 'intersubjetividade’. Mesmo na discordância dos pontos de vista e dos resultados das pesquisas, é possível o diálogo entre pesquisadores, pois cada um sabe o que o outro pretende e o que ele conseguiu ou não conseguiu e o que ele deveria fazer para conseguir o que queria ou o que impediu que, mesmo tendo atingido seu objetivo, seus resultados fossem divergentes do de outras pesquisas (REIS, 2000, p. 75-76) ${ }^{9}$.

\footnotetext{
${ }^{9}$ A intersubjetividade proposta pela Escola dos Annales pode ser vislumbrada a partir da própria postura de Febvre, um dos idealizadores do movimento referido, ao qual se atribui o mérito de não assumir uma posição radical em
} 


\section{A POLIFONIA PROCESSUAL: UMA APROXIMAÇÃO DO PROCESSO PENAL E DO INTERROGATÓRIO DO ACUSADO COM A METODOLOGIA EMPREENDIDA PELA ESCOLA DOS ANNALES}

À luz do direito e com o propósito de ilustrar que a correlação entre a polifonia dos Annales e a essência do processo, mormente do processo penal, não é apenas atual, mas estrutural, segue pesada crítica ao juiz solipsista e a concepções ou teorias, como a insculpida por Bülow, do processo como relação jurídica, que enaltece o julgador em prejuízo das partes:

DESDE JÁ, VALE DESTACAR QUE FALAR POR ÚLTIMO, ALINHAR OS SIGNIFICANTES PROBATÓRIOS, ENFIM, CONCLUIR, SIGNIFICA ATRIBUIR UM SENTIDO NO ESPAÇO DA FALA E, NESSE LUGAR, A TEORIA DA RELAÇÃO JURÍDICA (OSKAR VON BÜLOW), FAZ COM QUE O MAGISTRADO DOMINE E SINTA-SE LIVRE PARA DIZER O QUE QUISER, COMO BEM CRITICA LENIO STRECK. ENTRETANTO, ATRIBUIR SENTIDO NO ESPAÇO PÚBLICO NÃO SE COMPARA COM O ESPAÇO PRIVADO E O CONSTRANGIMENTO DO CONTRAditório E DO DIREITO VISTO COMO INTEGRIDADE (DWORKIN). PODEM, QUEM SABE, NOS SEGUIR POR CAMINHOS MAIS DEMOCRÁTICOS. UM AMOR PELO CONTRADITÓRIO É CONDIÇÃo DE POSSIBILIDADE. DE DESAMOR AO CONTRAdITÓRIO, OS EXEMPLOS SÃo MUITOS. PODERÁ SIGNIFICAR UMA FERIDA NARCÍSICA MORTAL AO MAGISTRADO QUE PENSA (E CANTA) “ESSE CARA SOU EU”. ROLAND BARTHES DIZIA QUE O “DISCURSO AMOROSO É HOJE EM DIA UMA EXTREMA SOLIDÃO”, AQUI COMPARTILHADA POR DOIS PROFESSORES DE Processo Penal QUe APOSTAM No AMOR (IM)POSSíVEl AO CONTRAditório. (LOPES JÙNIOR; DA ROSA, 2014, ONLINE).

Mas, para a salutar defesa da polifonia, há exemplos práticos, como o seguinte, do Excelso Pretório:

O acusado tem o direito de comparecer, de presenciar e de assistir, sob pena de nulidade absoluta, aos atos processuais, notadamente àqueles que se produzem na fase de instrução do processo penal, que se realiza, sempre, sob a égide do contraditório. São irrelevantes, para esse efeito, as alegações do Poder Público concernentes à dificuldade ou inconveniência de proceder ao custeio de deslocamento do réu militar, no interesse da Justiça, para fora da sede de sua Organização Militar, eis que razões de mera conveniência administrativa não têm - nem podem ter - precedência sobre as

face do conhecimento. Ao contrário, “[...] procura manter-se o mais aberto possível e pronto para acolher cada parcela de verdade que todo pensamento ( e não apenas um ) traz em seu bojo. Para que isto se concretize, o procedimento mais maduro é circunstanciar os pensamentos que se quer analisar dentro do amplo quadro histórico que lhe deu origem”. (MOTA, 1978, p. 14). 
inafastáveis exigências de cumprimento e de respeito ao que determina a Constituição. Doutrina. Jurisprudência. - O direito de audiência, de um lado, e o direito de presença do réu (civil ou militar), de outro, esteja ele preso ou não, traduzem prerrogativas jurídicas essenciais que derivam da garantia constitucional do ‘due process of law' e que asseguram, por isso mesmo, ao acusado o direito de comparecer aos atos processuais a serem realizados perante o juízo processante, ainda que situado este em local diverso daquele da sede da Organização Militar a que o réu esteja vinculado. Pacto Internacional sobre Direitos Civis e Políticos/ONU (Artigo 14, n. 3, “d”); Convenção Americana de Direitos Humanos/OEA (Artigo 8, § 2, “d” e “f”); e Decreto $\mathrm{n}^{\circ}$ 4.307/2002 (art. 28, inciso I). - Essa prerrogativa processual reveste-se de caráter fundamental, pois compõe o próprio estatuto constitucional do direito de defesa, enquanto complexo de princípios e de normas que amparam qualquer acusado em sede de persecução criminal, seja perante a Justiça Comum, seja perante a Justiça Militar. Precedentes. (BRASIL, 2014, online).

A polifonia, traduzida em democracia intraprocessual, não é apenas necessária, mas é da própria essência do processo penal constitucionalmene concebido.

\section{CONSIDERAÇÕES FINAIS}

A polifonia, presente no estudo da história a partir do advento da Escola dos Annales, revolucionou a maneira de pensar e fazer história trazendo para o discurso os diversos pontos de vista de todas as camadas sociais. Na medida em que se romperam as barreiras existentes na história tradicional política, centrada num discurso monofônico daqueles que reproduziam o discurso apenas e tão somente das grandes lideranças, o contraditório foi estimulado e passou a fazer parte da narrativa empreendida por historiadores e cientistas sociais modernos.

Empreende-se assim uma verdadeira associação entre a metodologia histórica apregoada pela Escola dos Annales e a ideia moderna, consoante o Estado constitucional, de que as decisões dos órgãos estatais devem ser construídas, a partir do discurso desenvolvido em nível processual, por todos aqueles interessados no provimento final, seja ele legislativo, administrativo ou jurisdicional.

No caso do processo penal, a polifonia representa, acima de tudo, a oitiva do acusado num interrogatório permeado de garantias para que o seu ponto de vista seja levado em conta no momento da decisão, o que acaba por afastar, procedimentalmente, o tradicionalismo monofônico de uma sentença centrada apenas no solipsismo do juiz. 


\section{A POLIFONIA PROCESSUAL: UMA APROXIMAÇÃO DO PROCESSO PENAL E DO INTERROGATÓRIO DO ACUSADO COM A METODOLOGIA EMPREENDIDA PELA \\ ESCOLA DOS ANNALES}

Eis a contribuição do texto: a polifonia, a oitiva e o respeito à inclusão dos sujeitos processuais é fator determinante e constitutivo da formação das decisões no processo penal constitucional. À similitude da Escola dos Annales, é necessário o repúdio às decisões solipsistas, fulcradas apenas e tão somente nos sentimentos e concepções de um único personagem do processo.

\section{REFERÊNCIAS}

ALTAVILLA, Enrico. Psicologia judiciária: personagens do processo penal. 3 ed. Tradução Fernando Miranda. Coimbra: Armênio Amado editor, 1981, v. 2.

ANDOLINA, Ítalo Augusto. O papel do processo na atuação do ordenamento constitucional e transnacional. Tradução de Oreste Nestor de Souza Laspro. Revista de Processo, Brasília, n. 87, p. 63-69, jul./set. 1997.

VIGNERA, Giuseppe. Il modello costituzionale del processo civile italiano. Torino: Giappichelli, 1990.

BOBBIO, Norberto. A era dos direitos. Rio de Janeiro: Campus, 1992.

BRASIL. Supremo Tribunal Federal. Agravo Regimental em Habeas Corpus. Processo n. 111567. Agravante: Ministério Público Federal. Agravado: Danilo do Prado Oliveira e outros. Relator: Ministro Celso de Mello. Disponível em:

<http://stf.jus.br/portal/jurisprudencia/listarJurisprudencia.asp?s1=\%28HC+86634\%29\&base=baseAcordaos\&ur l=http://tinyurl.com/yby824ys> Acesso em: 4 mar. 2018.

BURKE, Peter. A escola dos annales ( 1929-1989 ): a revolução francesa da historiografia. Tradução Nilo Odalia. São Paulo: UNESP, 1997. Mais, p. 18.

Desafios de uma história polifônica. Folha de São Paulo. São Paulo, 15 outubro 2000.

CANOTILHO, Joaquim José Gomes. Direito constitucional. 6. ed. Coimbra: Almedina, 1993.

CARNELUTTI, Francesco. As misérias do processo penal. Tradução de Luiz Fernando Lobão de Morais. Campinas: Edicamp, 2002.

CINTRA, Antônio Carlos de Araújo; GRINOVER, Ada Pellegrini; DINAMARCO, Cândido Rangel. Teoria geral do processo. 19. ed. São Paulo: Malheiros, 2003.

COSTA, Beatriz Souza; SAMPAIO, José Adércio Leite. Acesso à informação digital no Brasil em casos de acidentes: o exemplo da tragédia de Mariana. Veredas do Direito, Belo Horizonte, 
v. 14, n. 30, p. 77-98, set./dez. 2017. Disponível em: http://www.domhelder.edu.br/ revista/index.php/veredas/article/view/1126>. Acesso em: 3 mar. 2018.

DINAMARCO, Cândido Rangel. A instrumentalidade do processo. 11. ed. São Paulo: Malheiros, 2003.

FAZZALARI, Elio. Istituzioni di diritto processuale. Padova: Cedam, 1975.

GONÇALVES, Aroldo Plínio. Técnica processual e teoria do processo. Rio de Janeiro: AIDE Editora, 2001.

GRINOVER, Ada Pellegrini. O processo constitucional em marcha. São Paulo: Max Limonad, 1985.

HABERMAS, Jürgen. O estado nação europeu frente aos desafios da globalização. Revista Novos Estudos. São Paulo: CEBRAP, n. 43, nov. 1995, p. 87-101.

HADDAD, Carlos Henrique Borlido. O interrogatório no processo penal. Belo Horizonte: Del Rey, 2000.

LE GOFF, Jacques. A história nova. Tradução Eduardo Brandão. São Paulo: Martins Fontes, 2005.

LOPES JÚNiOR, Aury; DA ROSA, Alexandre Morais. Contraditório nO PROCESSO PENAL NÃO É AMOR, MAS É TÃO COMPLEXO QUANTO. DisPONÍVEL EM: < HTTPS://WWW.CONJUR.COM.BR/2014-JUN-13/CONTRADITORIO-PROCESSO-PENAL-NAOAMOR-TAO-COMPLEXO-QUANTO>. ACESSO EM: 2 MAR. 2018.

MARQUES, José Frederico. Elementos de direito processual penal. 2. ed. Campinas: Bookseller, 1998. v. 1.

MOTA, Carlos Guilherme. Lucien Febvre: história. São Paulo: Ática, 1978.

NUNES, Dierle José Coelho. O princípio do contraditório. Revista Síntese de Direito Civil e Processual Civil. Porto Alegre, n. 29, p.73-85, maio/jun. 2004.

OLIVEIRA, Carlos Alberto Álvaro. O juiz e o princípio do contraditório. Revista de Processo. Brasília, n. 71, p. 31-38, jul./set. 1993.

OLIVEIRA, Eugênio Pacelli de. Processo e hermenêutica na tutela penal dos direitos fundamentais. Belo Horizonte: Del Rey, 2004.

REIS, José Carlos. A escola dos annales: a inovação em história. São Paulo: Paz e Terra, 2000.

RIBEIRO, Luiz Gustavo Gonçalves. Práticas processuais penais: uma contribuição para a adequação constitucional da persecução penal. Belo Horizonte: Del Rey, 2013. 
SCHAFF, Adam. História e verdade. Tradução Maria Paula Duarte. São Paulo: Martins Fontes, 1978.

VARGAS, José Cirilo de. Processo penal e direitos fundamentais. Belo Horizonte: Del Rey, 1992. 